\title{
KELL BLOOD GROUP ANTIGENS IN THE BLOOD DONORS ATTENDING BLOOD BANKS OF TERTIARY CARE HOSPITALS OF LAHORE, PAKISTAN.
}

1. MBBS, M.Phil Hematology Assistant Professor Hematology Department of Pathology Nishtar Medical University \& Hospital, Multan.

2. MBBS, FCPS Hematology Professor

Department of Hematology Shaikh Zayed Medical Complex Lahore.

3. MBBS, FCPS Hematology Demonstrator Department of Pathology King Edwards Medical University \& Hospital, Lahore.

4. MBBS, M.Phil Hematology Assistant Professor Department of Pathology Rahber Medical \& Dental College, Lahore.

5. MBBS, M.Phil Hematology Assistant Professor Pathology Department of Pathology Ibn-e-Sina Hospital, Multan Medical \& Dental College, Multan.

6. MBBS, FCPS Hematology Assistant Professor Pathology Department of Pathology Nishtar Medical College, Multan.

Correspondence Address:

Dr. Sabeen Fatima Department of Pathology

Nishtar Medical University \& Hospital Multan.

sabeeenfatima@hotmail.com

Article received on:

10/08/2018

Accepted for publication:

15/12/2018

Received after proof reading: 25/06/2019

\section{Sabeen Fatima ${ }^{1}$, Mona Aziz², Sindhu Rehman ${ }^{3}$, Maliha Asif ${ }^{4}$, Naseem Akhter ${ }^{5}$, Yasmeen Batool ${ }^{6}$}

ABSTRACT... Among the complications of blood transfusion, Hemolytic transfusion reactions (HTRs) and Hemolytic disease of the newborn (HDN) are particularly important. Literature reports frequency of HTRs and related mortality up to $1 / 76,000$ and $1 / 1.8$ million units transfused respectively. These hemolytic reactions are caused by incompatibility between the donor and recipient blood and in cases of HDN, due to feto-maternal incompatibility due to maternal antibodies attacking the fetal red cells. Anti-K antibody is the most common antibody encountered in blood banks after the $\mathrm{ABO}$ and $\mathrm{Rh}$ antibodies. So routine screening and matching of these blood antigens along with $A B O$ and $\mathrm{Rh}$ can further reduce the risk of HTRs and HDN. Existing literature on Kell blood system reports varying frequency of $K$ and $\mathrm{k}$ antigens among various populations. The objectives of this study were to determine the prevalence of Kell blood group antigens in the blood donor population at Shaikh Zayed and Jinnah Hospitals Lahore and the association of Kell blood group antigens with different ABO blood groups of Lahore population. Study Design: It is a descriptive cross-sectional study. Setting: Research was conducted at the Blood banks of Sheikh Zayed Hospital, Lahore and Jinnah Hospital, Lahore. Period: 6 months after the approval of synopsis from 15/06/2015 to 15/12/2015. Material and Methods: This study included 192 donors; 96 from Sheikh Zayed Hospital, Lahore and 96 from Jinnah Hospital, Lahore. A written informed consent was taken from every donor. Kell blood group antigens $\mathrm{K}$ and $\mathrm{k}$ were determined. Results: There were 192 donors, 96 each from Shaikh Zayed Hospital, Lahore and Jinnah Hospital, Lahore. Out of these donors $186(96.9 \%)$ were males and 6 (3.1\%) were females. The most frequent $A B O$ blood group antigen observed was $B$, which was seen in $82(42.7 \%)$ donors, followed by $\mathrm{O}$ in $68(35.4 \%), \mathrm{A}$ in $36(18.8 \%)$ and $\mathrm{AB}$ in $06(3.1 \%)$ donors. Kell antigen $\mathrm{k}$ was found in $185(96.3 \%)$ donors while $\mathrm{K}$ was found in 07 (3.6\%) donors. When stratified, there was no statistically significant difference in the frequency of Kell antigens between genders $(p=0.08)$ and $A B O$ blood groups (0.09). The frequency of $k$ antigen was higher among those with blood group $B(43.2 \%$ vs. $17.8 \%)$ as compared to $A$, and the frequency of $K$ antigen was higher among those with blood group $A(42.8 \%$ vs. $28.5 \%)$ as compared to $B$, however, this was statistically insignificant. Conclusion: The frequency of $\mathrm{k}$ was observed to be $96.3 \%$. It was higher in donors with antigen $B$ while the frequency of $\mathrm{K}$ was found to be $3.6 \%$ and it was higher in donors with antigen $A$.

Key words: $\quad$ ABO Blood Group, Kell Blood Group, Multiple Transfusions, Transfusion Reaction.

Article Citation: Fatima S, Aziz M, Rehman S, Asif M, Akhter N, Batool Y. Kell blood group antigens in the blood donors attending blood banks of tertiary care hospitals of Lahore, Pakistan. Professional Med J 2019; 26(7):1167-1171. DOI: 10.29309/TPMJ/2019.26.07.3792

\section{INTRODUCTION}

There are more than 33 blood groups that represent over 300 red blood cell antigens. ${ }^{1}$ Other than two major important $\mathrm{ABO}$ and $\mathrm{Rh}$ antigens many other significantly important red blood cell antigens also exist. It is important to have knowledge of frequencies of various blood group antigens and their association with each other in order to find out their ethnic distribution and assess the risk of antibody formation to help guide about the probability of finding blood that is negative for that antigens especially in cases in which a patient has various red cell alloantibodies due to multiple transfusions. ${ }^{2}$ Therefore, the blood units in the blood banks should be typed not only for major but also minor blood antigens in order to increase in vivo survival rates and prevent adverse hemolytic transfusion reactions. ${ }^{3}$ 
Kell antibodies are 3rd most potent in producing an immunogenic response after $A B O$ and $R h$ antibodies. $^{4}$

Kell blood group system consists of 35 antigens, including six sets of antigens termed as $\mathrm{K}, \mathrm{k}, \mathrm{Kpa}$, $\mathrm{Kpb}$, Jsa and Jsb with antithetical relationships. ${ }^{5}$ The Kell antigens can be found as early as 10 weeks of gestation in the fetus and therefore plays a significant role in hemolytic disease of the newborn, transfusion reactions and transfusion medicine. ${ }^{6}$

Anti-K antibody belongs to the IgG class of antibodies and is usually produced in response to antigen exposure during pregnancy or previous transfusions. The significance of Kell antigen and antibodies is evident from the fact that they play an important role in hemolytic transfusion reactions and also are a major culprit of hemolytic disease of the newborn. ${ }^{7}$

HDN is actually an immunologic response in which allogenic paternal proteins that are expressed on the RBCs of the developing fetus have the capability to produce IgG alloantibodies in the mother against that particular antigen. The first pregnancy is usually spared since only exposure to that antigen occurs in it, with transfer of maternal IgG antibodies to fetus with subsequent pregnancies leads to antibody mediated destruction of RBCs of fetus. However, it is not a must since previous transfusion of women of child bearing age with mismatched blood can lead to antibody production in such women and hence can lead to deleterious effects in first pregnancy too. ${ }^{8}$

Less data is available regarding frequency of blood group antigens other than $A B O \& R h$ systems in Pakistani population. The knowledge of various antigen frequencies is very pertinent to assess the risk of antibody formation ${ }^{9}$ to help in the provision of antigen negative blood which is especially useful when blood is required for patient who have multiple RBC antibodies. Kell negative blood may also be helpful for people undergoing bone marrow transplantation, which were previously transfusion dependent and have developed antibodies against antigens other than $\mathrm{ABO}$ and $\mathrm{Rh}$.

\section{OBJECTIVES}

The objectives of this study were

1. To determine Kell blood group antigens in the blood donor population at Shaikh Zayed and Jinnah Hospital Lahore.

2. To see the association of Kell blood group antigens with different $\mathrm{ABO}$ blood groups of Lahore population.

3. To reduce the chance of Kell related transfusion reactions.

\section{METHODOLOGY}

It was a descriptive crossectional study conducted at the Blood banks of Shaikh Zayed and Jinnah Hospital Lahore with a duration of 6 months after the approval of synopsis from $15 / 05 / 2015$ to $15 / 12 / 2015$. Blood donors aged 18-60 years of either sex having $\mathrm{Hb} \geq 13 \mathrm{~g} / \mathrm{dL}$ for males, $\geq 12 \mathrm{~g} / \mathrm{dL}$ for females and weight above $50 \mathrm{Kgs}$ were included in our descriptive crossseectional study using non-probability purposive sampling technique. A total of 192 blood donors were included, sample size was estimated by using $95 \%$ confidence level and $2.6 \%$ margin of error with expected frequency of $\mathrm{K}$ was $3.5 \%$. Patients having Bone marrow, haemopoietic stem cell, renal, heart or any other transplant recipients and suffering from autoimmune disorders like systemic lupus erythmatosis, antiphospholid syndrome etc were excluded from our study. Data of blood donors, visiting blood bank of Shaikh Zayed and Jinnah Hospital, Lahore, were collected, after filling consent forms and proforma (Annex I, II, III). Determination of CBC, Kell phenotype and weight measurement was done. All the collected data was entered into SPSS version 20. Categorical variables i.e gender, $A B O$ antigens, $\mathrm{K}$ and $\mathrm{k}$ antigens have been presented by frequency and percentages. Frequency of $K$ and $k$ have been cross tabulated with $A B O$ antigens to determine association between Kell antigens and $A B O$ antigens. Data has been stratified for gender and $\mathrm{ABO}$ status to address effect modifiers. Post-stratification chi-square has been applied taking $p$ value $\leq 0.05$ as significant. 


\section{RESULTS}

This study included 192 donors; 96 from Sheikh Zayed Hospital and 96 from Jinnah Hospital, Lahore. Age of the donors ranged from 18 years to 51 years. The donors were divided into 5 groups, I (11-20years), II (21-30 years), III (31-40 years), IV (41-50years), V (51-60 years) according to their decades. Most of the patients were from group II $(n=105,54.7 \%)$. There were $186(96.9 \%)$ male and 06 (3.1\%) female donors in the study group. The most frequent $A B O$ blood group antigen observed was $B$ antigen seen in 82 $(42.7 \%)$ donors, followed by $\mathrm{O}$ in $68(35.4 \%), \mathrm{A}$ in 36 (18.8\%) and $A B$ in 06 (3.1\%) ABO blood group antigens. When the frequency of $A B O$ blood group antigens was stratified, there was no significant difference in terms of donor age groups $(p=0.81)$ and gender $(p=1.66)$ respectively. $K$ was found in 185 (96.3\%) donors while $\mathrm{K}$ was observed in only $07(4.7 \%)$ donors. When stratified, there was no statistically significant difference in the frequency of Kell antigens between genders $(p=0.08)$ and $A B O$ blood groups $(p=0.09)$ respectively. However, the frequency of $k$ antigen was higher among those with antigen $B(43.2 \%$ vs. $17.8 \%)$ as compared to $A$, whereas the frequency of $K$ antigen was higher among those with antigen $A$ ( $42.8 \%$ vs. $28.5 \%)$ as compared to B.

\section{DISCUSSION}

Among acute complications of mismatched transfusion, acute hemolytic transfusion reactions (AHTRs) are particularly important. Literature reports frequency of AHTRs and related mortality up to $1 / 76,000$ and $1 / 1.8$ million units transfused, respectively ${ }^{10}[313]$. The most commonly typed grouping systems are $\mathrm{ABO}$ and $\mathrm{Rh}$, and donors are routinely matched with the recipient on these systems.

Anti-K antibody is the most common antibody encountered in blood banks after the $A B O$ and Rh antibodies. ${ }^{4}$ It belongs to the IgG class of antibodies and is usually produced in response to antigen exposure during pregnancy or previous transfusions. Existing literature reports varying frequency of $\mathrm{K}$ and $\mathrm{k}$ antigens among various populations.
This study included 192 donors; 96 from Sheikh Zayed Hospital, Lahore and 96 from Jinnah Hospital, Lahore. The age of the donors was 18-51years. There were $186(96.9 \%)$ male and 6 (3.1\%) female donors. Shah et al. in 2013 also observed similar male predominance among blood donors (85\% Males; vs. $15 \%$ Females) in Kashmir. ${ }^{11}$ On the other hand, Mustafa et al. in 2014 reported nearly equal proportion of donors from both genders (54\% Males vs.46\% Females) in Saudi Arabia. ${ }^{12}$ This male predominance in our society can be attributable to poor nutritional and health status of women in general along with myths and phobias about the blood donation and educational status of population. ${ }^{13}$

The most frequent $\mathrm{ABO}$ blood group antigen observed was $B$ seen in $82(42.7 \%)$ donors, followed by $O$ in 68 (35.4\%), $A$ in 36 (18.8\%) and $A B$ in 06 (3.1\%) donors. Shah et al. however observed $O(35.6 \%)$ to be the most common blood group among Kashmiri population followed by $B(32.1 \%), A(24.1 \%)$ and $A B(8.2 \%) .{ }^{11}$ This difference can be due to genotypic differences among populations.

$k$ antigen (Cellano) was found in 185 (96.3\%) donors. Our results match with those of another local study by Ashraf et al. (2001) who observed this frequency to be $93.8 \%$ in Karachi population. ${ }^{14}$ While Rani et al. (2015) in India reported it to be $96.8 \%{ }^{15}$, Makroo et al. (2013) in India and Mustafa et al. (2014) in Saudi Arabia, both reported the frequency of $k$ antigen to be $99.9 \%$. $^{3,12}$

When stratified, there was no statistically significant difference in the frequency of Kell antigens between age groups $(p=0.98)$, genders $(p=0.08)$ and blood groups $(p=0.09)$ However, the frequency of $k$ antigen was found higher among those with blood group B (43.2\% vs. $17.8 \%$ ) as compared to A. Ashraf et al. (2001) also observed $k$ to be significantly higher among group B as compared to A. ${ }^{14}$

In our study K was observed in only 07 (3.6\%) donors. Our results are again similar to those of Ashraf et al. in which $\mathrm{K}$ was observed to be $(4.6 \%) .{ }^{14}$ Shah et al. in Kashmir reported quiet 
lower frequency of only $0.03 \%{ }^{11}$, however, Mustafa et al. (2014) reported it to be quite high (9\%) in Saudi Arabia. ${ }^{12}$ Makroo et al. (2013) and Rani et al (2015) in India, Wagner et al. (1995) report in Germany and Akasha et al. (2012) in Sudan reported it to be $3.5 \%, 3.15, \% 4 \%$ and $5.6 \%$ in their respective populations. ${ }^{3,14,16,17}$

However, the frequency of $\mathrm{K}$ antigen was higher among those with antigen A (42.8\% vs $28.5 \%)$ as compared to $B$, but this was statistically insignificamt. Our results match with those of Shah et al. (91.70\% vs. $85.18 \%)$ and Ashraf et al. who also observed $K$ to be significantly frequent among blood group $\mathrm{A}$ as compared to B. ${ }^{11,14}$ While Rani et al. in India observed no marked difference (3.49\% vs. $3.23 \%) .{ }^{15}$

To conclude, we observed Kell antigens $\mathrm{K}$ and $\mathrm{k}$ in $3.6 \%$ and $96.3 \%$ of blood donors respectively presenting at blood banks of Sheikh Zayed Hospital, Lahore and Jinnah Hospital, Lahore. Compared to Shah et al. (0.3\%) in Kashmir, we observed much higher frequency of $\mathrm{K}$ antigen in Pakistani donors. ${ }^{11}$ This higher frequency of $\mathrm{K}$ in local population and lack of screening and matching can partly explain the increased frequency of hemolytic transfusion reactions noticed in the common practice. It can be thus advocated on the basis of our study, that Kell blood group antigens should be routinely screened and cross-matched; to reduce the risk of such transfusion related reactions in future practice.

We also observed a co-existance of blood group $A$ with Kell antigen $\mathrm{K}$ and blood group $\mathrm{B}$ with Kell antigen $\mathrm{k}$, although these findings donot show statistical significance, but presence of HTR with group $A$ and $B$ transfusions can be associated with Kell system antibodies in receipients and if not all atleast such transfusions should be checked for Kell antigen in donor and respective antibodies in receipients.

Keeping in view the variations observed in the frequency of $\mathrm{K}$ and $\mathrm{k}$ antigens among studies from various parts of the India ${ }^{3,15}$ depicting variation within a single population, it is advisable that the present study should be repeated over much larger sample size, covering multiple blood banks from various areas of Pakistan to determine the frequency of Kell antigens more accurately.

\section{CONCLUSION}

The frequency of $\mathrm{k}$ was observed to be $96.3 \%$. It was higher in donors with antigen $\mathrm{B}$ while the frequency of $\mathrm{K}$ was found to be $3.6 \%$ and it was higher in donors with antigen $A$.

Copyright $@ 15$ Dec, 2018.

\section{REFRENCES}

1. M Ranadhir, M Nitasha, Rath GP. Blood group systems. Indian J Anaesth. 2014 Sep-Oct; 58(5): 524-28.

2. Hassan K, Younus M, Ikram N, et al. Red cell alloimmunization in repeatedly transfused thalassemia major patients. Int J Pathol Jun 2004; 2(1):16-9.

3. Makroo R.N, Bhatia A, Gupta R, Phillip J. Prevalence of Rh, Duffy, Kell, Kidd \& MNSs blood group antigens in the Indian blood donor population. Indian J Med Res 2013; 137(3):521-26.

4. Dean L. "The Kell blood group -- Blood groups and red cell antigens". NCBI Bookshelf. National Center for Biotechnology Information - United States National Institutes of Health. Retrieved 2009-05-04.

5. Daniels G. (2013). Kell and Kx blood group systems, in human blood groups, 3rd edition, Wiley-Blackwell, Oxford, UK. doi: 10.1002/9781118493595.ch7.

6. Contreras M, Daniels G. Red cell immunohaematology: Introduction. In: Hoffbrand AV, Catovsky D, Tuddenham EGD, eds. Postgraduate Haematology, 5th edn. Oxford: Blackwell, 2005:207-24.

7. Gilbert ER. A critique of the theoretical hazards of inter vs intra-racial transfusions. Transfusion 1961:1:233-28.

8. Mayne KM, Bowell PJ, Pratt Ga. The significance of anti-kell sensitization in pregnancy. Clin Lab Haematol 1990:12:379-85.

9. Agarwal N, Thapliyal RM, Chatterjee K. Blood group phenotype frequencies in blood donors from a tertiary care hospital in north India. Blood research 2013; 48(1):51-54.

10. Strobel E. Hemolytic transfusion reactions. Transfus Med Hemother 2008; 35:346-53. 
11. Shah M, Shah FY, Shah FY. Incidence of Kell blood group in Kashmiri population attending blood bank SKIMS as donors. Ann Trop Med Public Health 2013; 6:183-7.

12. Mustafa IHM, Elmahdi TE, Salim AM, Ahmed MM, Bushara SO. Distribution of kell blood group system antigens Kpa, Kpb in major tribes of Turaba ProvinceKSA. J Int Multi Cur Res 2014; 2:1147-50.

13. Ashraf S, Moinuddin. Kell blood group: A population based study. Pak J Med Sci 2001; 17: 211-4.
14. Bogui LS, Dembele B, Sekongo Y, Abisse S, Konaté S, Sombo M. Phenotypic profile of $\mathbf{R h}$ and Kell blood group systems among blood donors in Cote d'Ivoire, West Africa. J Blood Transfus 2014; 2014:309817.

15. Wagner FF, Kasulke D, Kerowgan M, Flegel WA. Frequencies of the blood groups $A B O$, Rhesus, D category VI, Kell, and of clinically relevant highfrequency antigens in south-western Germany. Infusionsther Transfusions med 1995; 22: 285-90.

16. Akasha AS. The frequency of Kell red cell antigens $(K, k)$ among the major Sudanese tribes. Recent Res Sci Technol 2012; 4: 44-5.

\section{AUTHORSHIP AND CONTRIBUTION DECLARATION}

\begin{tabular}{|c|c|c|c|}
\hline Sr. \# & Author-s Full Name & Contribution to the paper & Author $=$ s Signature \\
\hline 1 & Sabeen Fatima & $\begin{array}{l}\text { Study design, data collection, writing } \\
\text { the manuscript, formaulation of tables } \\
\text { reviewed and approval. }\end{array}$ & \\
\hline 2 & Mona Aziz & $\begin{array}{l}\text { Study design, statistical analysis, } \\
\text { result interpretation, manuscript } \\
\text { writing and revising it critically for } \\
\text { important intellectual content. }\end{array}$ & \\
\hline 3 & Sindhu Rehman & $\begin{array}{l}\text { Data collection, formulation of tables } \\
\text { reviewed and approved the manuscri. }\end{array}$ & \\
\hline & & $\begin{array}{l}\text { Statistical analysis, interpretation of } \\
\text { results, Reviewed and approved the } \\
\text { manuscript. }\end{array}$ & H. ANA \\
\hline 4 & Maliha Asif & $\begin{array}{l}\text { Manuscript writing interpretation of } \\
\text { results and formulation of results. }\end{array}$ & \\
\hline 5 & Naseem Akhter & $\begin{array}{l}\text { Statistical analysis, manuscript writing } \\
\text { and result interpretation. }\end{array}$ & \\
\hline 6 & Yasmeen Batool & $\begin{array}{l}\text { Manuscript writing formulation of } \\
\text { talbles. }\end{array}$ & \\
\hline
\end{tabular}

